\title{
Botany
}

American Journal of Botany 100(4): 792-800. 2013.

\section{MiCroorganisms TRANSPORTED BY ANTS INDUCE CHANGES IN FLORAL NECTAR COMPOSITION OF AN ANT-POLLINATED PLANT ${ }^{1}$}

\author{
Clara de Vega² and Carlos M. Herrera
}

Estación Biológica de Doñana, Consejo Superior de Investigaciones Científicas (CSIC), Avenida de Américo Vespucio s/n 41092 Sevilla, Spain

\begin{abstract}
- Premise of the study: Interactions between plants and ants abound in nature and have significant consequences for ecosystem functioning. Recently, it has been suggested that nectar-foraging ants transport microorganisms to flowers; more specifically, they transport yeasts, which can potentially consume sugars and alter nectar composition. Therefore, ants could indirectly change nectar sugar profile, an important floral feature involved in the plant-pollinator mutualism. But this novel role for ants has never been tested. We here investigate the effects of nectarivorous ants and their associated yeasts on the floral nectar sugar composition of an ant-pollinated plant.

- Methods: Differences in the nectar sugar composition of ant-excluded and ant-visited flowers were examined in 278 samples by using high-performance liquid-chromatography. The importance of the genetic identity and density of ant-transported basidiomycetous and ascomycetous yeasts on the variation of nectar traits was also evaluated.

- Key results: Ant visitation had significant effects on nectar sugar composition. The nectar of ant-visited flowers contained significantly more fructose, more glucose, and less sucrose than the nectar of ant-excluded flowers, but these effects were context dependent. Nectar changes were correlated with the density of yeast cells in nectar. The magnitude of the effects of ant-transported ascomycetes was much higher than that of basiodiomycetes.

- Conclusions: Ants and their associated yeasts induce changes in nectar sugar traits, reducing the chemical control of the plant over this important floral trait. The potential relevance of this new role for ants as indirect nectar modifiers is a rich topic for future research into the ecology of ant-flower interactions.
\end{abstract}

Key words: ant-plant interactions; ant pollination; ascomycetes; basidiomycetes; Cytinus hypocistis; flower yeasts; nectar sugar composition; plant-pollinator interactions.

Ant-plant associations are important elements in most terrestrial habitats with crucial consequences for ecosystem processes (Rico-Gray and Oliveira, 2007). Possibly no other group of animal interacts with plants in such a variety of ways as ants do, and the nature of such interactions shifts from mutualism to antagonism as the costs and benefits vary (Huxley and Cutler, 1991; Beattie and Hughes, 2002; Rico-Gray and Oliveira, 2007). Sugary secretions produced by plants are largely involved in the relationships with ants since, for a wide variety of ant taxa, sugars are an important component of their diet (RicoGray, 1989; Blüthgen et al., 2000; Heil et al., 2005). Ants are the most abundant animals consuming the sugar-rich nectar from extrafloral nectaries, which are commonly located in leaves and occur mainly in tropical plants (Pacini and Nicolson, 2001), and in turn, ants potentially defend plants against herbivores (Beattie, 1985; Oliveira et al., 1999; Heil and McKey,

\footnotetext{
${ }^{1}$ Manuscript received 6 December 2012; revision accepted 4 February 2013.

The authors thank I. M. García and M. García for technical assistance in the laboratory and Dr. R. G. Albaladejo, Dr. M. Heil, and an anonymous reviewer for helpful comments on the manuscript. This work was supported by funds from Consejería de Innovación, Ciencia y Empresa, Junta de Andalucía (Proyecto de Excelencia P09-RNM-4517 to CMH), Ministerio de Ciencia e Innovación (grant CGL2010-15964 to CMH) and Juan de la Cierva Program to CdV.

${ }^{2}$ Author for correspondence (e-mail: cvega@ebd.csic.es), phone: +34 954466700 (ext. 1409), fax: + 34954621125
}

doi:10.3732/ajb.1200626
2003). The sugar-rich nectar of flowers is also an important food resource for ants, which are frequent floral-nectar foragers in many terrestrial ecosystems including tropical forests (Haber et al., 1981; Rico Gray, 1989; Rico-Gray et al., 1998; Blüthgen et al., 2004), alpine ecosystems (Norment, 1988; Gómez et al., 1996; Puterbaugh, 1998; Galen and Butchart, 2003), arid habitats (Hickman, 1974; Gómez et al., 1996), and mediterranean environments (Herrera et al., 1984; Gómez and Zamora, 1992; Gómez et al., 1996; de Vega et al., 2009a), where ants can even be the dominant flower-visiting insect group during the flowering season (Bosch et al., 1997). In many cases, ant visits to flowers do not confer any benefit to plants and could potentially even be costly for plant reproduction (Fritz and Morse, 1981; Beattie et al., 1984; Galen and Butchart, 2003; but see Norment, 1988). By this token, some morphological and chemical floral features have been interpreted as natural ant repellents (Guerrant and Fiedler, 1981; Ghazoul, 2001; Willmer et al., 2009). In spite of this, ants are avid nectar collectors in many plant species, and a growing number of studies demonstrate that, while foraging for nectar, ants can also pollinate the flowers (for references, see Rico-Gray and Oliveira, 2007; Rostás and Tautz, 2011).

Three main sugars - sucrose and its monomers, fructose and glucose-dominate nectar chemistry, and together with amino acids are the most important components for attracting floral visitors (Baker and Baker, 1983; Blüthgen and Fiedler, 2004; Nepi et al., 2012). Other substances such as proteins, lipids, other minor sugars, alkaloids, and secondary compounds generally appear only in trace amounts (Nicolson and Thornburg, 2007). The chemical composition of the secreted nectar is 
thought to be regulated by the plant, and sugar composition especially has been repeatedly described as a conservative character that can be functionally related to pollinator type (Baker and Baker, 1983; Goldblatt et al., 2001; Galetto and Bernardello, 2003). Sucrose is uploaded from the phloem sap or synthesized in the secretory tissue, and the final proportion of monosaccharides is mostly determined by nectary invertase that catalyzes the hydrolysis of sucrose into glucose and fructose, controlling the sucrose to hexose ratio of nectar (Nicolson and Thornburg, 2007; Heil, 2011). Recent studies, however, have opened up new lines of research on nectar chemistry by suggesting that nectar composition could be further modified by microorganisms, and more specifically nectar-dwelling yeasts, that consume sugars and other components (Canto et al., 2008; Herrera et al., 2008; Peay et al., 2012). Nectar-dwelling yeasts have been observed in plant species in tropical and temperate regions (Brysch-Herzberg, 2004; de Vega et al., 2009b, 2012; Herrera et al., 2009; Canto and Herrera, 2012) and even in flowers with secondary compounds that should potentially prevent microbial infections (Manson et al., 2007) implying that, to a certain degree, nectar sugar composition could be beyond the control of the plant.

Interestingly, ants have recently been recognized as effective yeast vectors between flowers (de Vega and Herrera, 2012). Different ant species carry both ascomycetous and basidiomycetous yeasts that could metabolize nectar sugars (de Vega and Herrera, 2012). So it is possible that with their continuous visits to flowers, ants further alter nectar chemical composition consistent with their role as yeast transporters. In addition to their function as legitimate pollinators and nectar thieves, ants could thus be playing an important but yet largely unknown role with respect to flowers as indirect nectar modifiers. Ants can be highly abundant on the flowers throughout the day and forage within the same plant for a long time (Hickman, 1974; Gómez et al., 1996; de Vega et al., 2009a), which would facilitate yeast transmission from their bodies to the nectar. Given the high number of plant species visited by nectar-collecting ants in many habitats (up to $40 \%$ in the tropics and $60 \%$ in mediterranean communities; Rico-Gray, 1989, 1993; Bosch et al., 1997; Rico-Gray et al., 1998), it becomes important to determine the potential effects of ants and their associated yeasts on nectar chemical traits, because yeast activity can trigger changes in the foraging behavior of floral visitors and alter the outcomes of plant-pollinator interactions (Herrera et al., 2013).
To date, the impact of insect visitors and associated microbes on nectar traits has only been suggested by correlational studies, in which no experimental manipulation was made, or which were conducted under artificial conditions that may not yield conclusive results (Herrera et al., 2008; Canto and Herrera, 2012; Peay et al., 2012). And their importance may also be variable in space and time. Additionally, the specific importance of the yeast taxa involved in nectar changes has not previously been taken into account, but osmotolerant and fermentative ascomycetous species are usually more adapted to the nectar conditions than basidiomycetous ones (Lachance, 2006) and consequently could trigger more extensive nectar changes. Thus experimental studies under natural field conditions are lacking. The experimental study presented here explores for the first time the effects of ant visitation and their associated yeasts on nectar sugar chemistry under field conditions.

The ant-pollinated plant Cytinus hypocistis L. (L.) (Cytinaceae) provides an ideal model plant with which to address three main objectives: (1) to determine whether ant-visited flowers differ in nectar sugar composition from unvisited flowers protected from ants and their associated yeasts, (2) to assess whether changes in nectar sugar composition vary spatially between populations, and (3) to evaluate the effect of abundance and identity of basidiomycetous and ascomycetous yeast species transported by ants on the variation in nectar sugar traits. Incorporating new roles common to nectarivorous ants into classic models of ant-plant interactions will contribute directly to our better understanding of mutualisms and will provide a framework for identifying areas for future research.

\section{MATERIALS AND METHODS}

Cytinus-ants-yeasts study system-Cytinus hypocistis is a perennial, parasitic plant with inflorescences that burst in spring through the host root tissues, exclusively in the Cistaceae family (de Vega et al., 2007, 2010). Inflorescences appear at ground level solely or in clusters of 1-22 on the same host root. Each inflorescence presents around six basal female flowers and six distal male flowers that last up to $6 \mathrm{~d}$. The mesenchymatous nectaries of $C$. hypocistis are connected to the phloem and the xylem and secrete nectar via modified stomata (de Vega, 2007). Female and male flowers produce similar amounts of nectar, with a daily nectar production of $\sim 1.5 \mu \mathrm{L}$ (de Vega, 2007).

Ants are the main pollinators of C. hypocistis (Fig. 1A) accounting for $97 \%$ of total floral visits, and plants exhibit high fruit-set and seed production under natural conditions (de Vega et al., 2009a, 2011). Among the most abundant daytime ant species visiting Cytinus flowers are Pheidole pallidula Nylander,
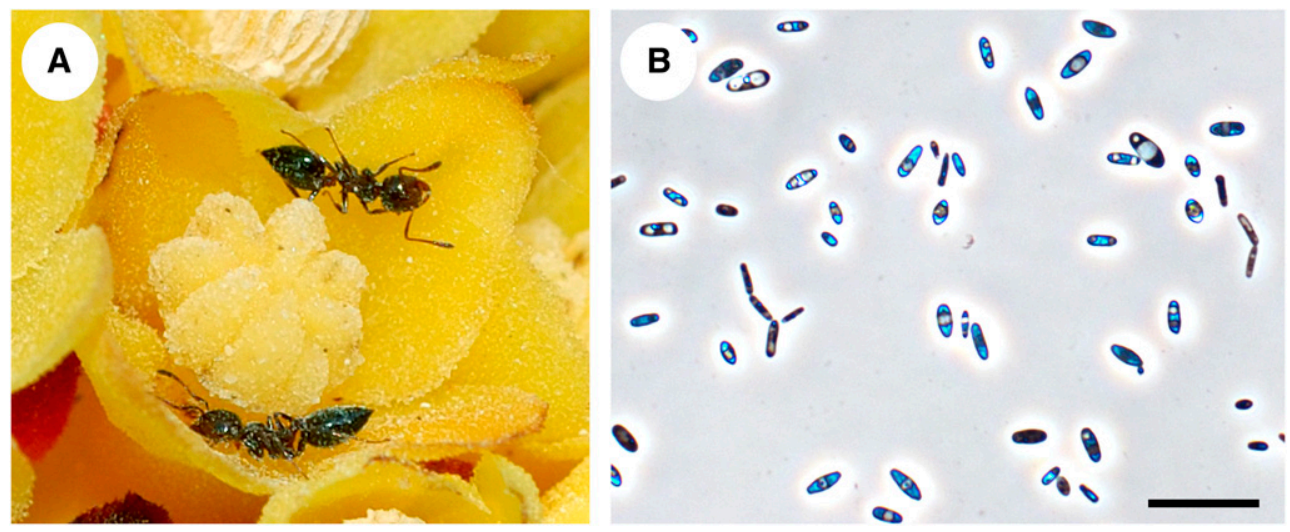

Fig. 1. Flowers of Cytinus hypocistis, ant pollinators, and associated yeasts. (A) Crematogaster auberti foraging on a female flower of $C$. hypocistis. (B) Yeasts isolated from nectar of $C$. hypocistis. Scale bar $=25 \mu \mathrm{m}$. 
Plagiolepis pygmaea Latreille, Crematogaster auberti Emery, Crematogaster scutellaris Olivier, and Aphaenogaster senilis Mayr, while Camponotus pilicornis Roger is a nighttime visitor (for further details see de Vega et al., 2009a).

Many ants are effective vectors of yeasts to $C$. hypocistis floral nectar (Fig. 1B), with $70 \%$ of yeast species transported on ant body surfaces occurring also in nectar (de Vega and Herrera, 2012). However, the nocturnal $C$. pilicornis did not carry viable yeasts. Yeasts were observed in the nectar of $77 \%$ of flowers and $94 \%$ of $C$. hypocistis plants exposed to ants, and both ascomycetous (with the main genera Metschnikowia Kamienski, Candida Berkhout, and Debaryomyces Lodder and Kreger van Rij) and basidiomycetous yeasts (mainly Cryptococcus Vuillemin, Rhodotorula Harrison, and Sporobolomyces Kluyver and van Niel) appeared in C. hypocistis nectar (de Vega and Herrera, 2012). The highest yeast densities appeared to be associated with ascomycetous yeasts and more specifically with the presence of the nectar-specialist Metschnikowia reukaufii Pitt and Miller. Flowers excluded from ants do not harbor any yeasts, indicating that ants are necessary for fungal infestation of nectar (de Vega and Herrera, 2012).

Study area-Cytinus hypocistis shows remarkable host specificity, and there are distinct genetic races that parasitize different host species (de Vega et al., 2008). This study was carried out in six natural populations involving three races of $C$. hypocistis parasitizing three Cistaceae host species: two populations parasitizing Cistus ladanifer $\mathrm{L}$. (race $\mathrm{Cl}$ hereafter), two populations on Cistus salviifolius L. (race Cs), and two populations on Halimium halimifolium (L.) Willk. (race Hh). Study populations were located in the surroundings of the Doñana National Park (SW Spain; $37^{\circ} 18^{\prime} \mathrm{N}, 6^{\circ} 25^{\prime} \mathrm{W}$ ). The populations, separated by $0.3-2.5 \mathrm{~km}$, grow at similar altitudes $(80-90 \mathrm{~m}$ a.s.l.) under similar climatic conditions. Yeasts occurred in all C. hypocistis populations, but nectar of plants belonging to race $\mathrm{Cl}$ shows lower yeast densities than those in races Cs and Hh (de Vega and Herrera, 2012).

Sampling design-In each race of $C$. hypocistis, two sets of plants were randomly selected. One set of plants was exposed to ants for $2 \mathrm{~d}$ and then bagged for $24 \mathrm{~h}$ to allow for nectar accumulation (ant-exposed plants; $N=169$ flowers; mean $\pm \mathrm{SE}=56.3 \pm 13.3$ flowers/race and $17 \pm 3.5$ plants/race). In the other set of plants, flowers were bagged in nylon mesh $(200 \mu \mathrm{m}$ mesh) before they opened to exclude insect visitors and kept bagged for $3 \mathrm{~d}$ until nectar sampling (ant-excluded plants; $N=109$ flowers; mean $\pm \mathrm{SE}=36.3 \pm 4.9$ flowers/ race and $11 \pm 1.5$ plants/race). All selected ant-excluded and ant-exposed plants had at least four male and four female flowers, and studied flowers were of similar age. Given that bags could deter ants from visiting other flowers on the same plant and that plants have a low flower number (ca. six flowers of each sex), nectar sampling of ant-excluded and ant-exposed flowers were conducted on different plants. Only one $C$. hypocistis plant per individual host plant was selected because plants bursting through the same host root can be either ramets of the same individual or genetically different individuals (de Vega, 2007).

After the treatments in the field, inflorescences were carried in a cooler to the laboratory where nectar was sampled within a few hours after collection. Nectar samples from two male and two female flowers per plant were collected on different plants in each population. Samples of nectar (mean $0.54 \pm 0.03 \mu \mathrm{L}$ for ant-exposed flowers and $1.62 \pm 0.17 \mu \mathrm{L}$ for ant-excluded flowers) were extracted with sterile micropipettes, its volume determined by the length of the nectar column and then blotted onto separate $10 \times 2 \mathrm{~mm}$ sterile chromatography paper wicks (Whatman 3MM, Maidstone, Kent, UK). Wicks were completely and immediately dried and then individually stored in sterile paper envelopes and stored in plastic bags containing silica gel until chemical analysis (Galetto and Bernardello, 2005). This technique for storing nectar has been widely used by biologists for subsequent nectar chemical analyses (e.g., Freeman and Wilken, 1987; Heil et al., 2000; Galetto and Bernardello, 2005; Herrera et al., 2006; Krömer et al., 2008; Canto and Herrera, 2012).

We had previously determined for subsamples of the same nectar samples yeast incidence and cell density by microscope observations and yeast identity by sequencing the D1/D2 domain of the 26S rDNA (see de Vega and Herrera, 2012 for further details). Thus, for each nectar sample, information on nectar chemical characteristics and yeast taxa was available.

Nectar chemical analyses-Nectar-impregnated wicks were removed from storage and soaked in $500 \mu \mathrm{L}$ of HPLC-grade water in 2-mL tubes during $24 \mathrm{~h}$ at $4^{\circ} \mathrm{C}$. Two microliters from each tube were then diluted $1: 100$ in HPLC-grade water. Five microliters of each dilution was filtered using a polyvinylidene difluoride filter ( $0.4 \mu \mathrm{m}$ pore; Análisis Vínicos SL, Tomelloso, Spain) and injected into a Dionex DX 500 HPLC system (Dionex, Sunnyvale, California, USA).
The HPLC system was equipped with an eluent degas module, a guard column CarboPac PA10 $(4 \times 50 \mathrm{~mm})$, a GP 40 gradient pump, an analytical column CarboPac PA10 $(4 \times 250 \mathrm{~mm})$, and an ED 40 electrochemical detector for pulsed amperometric detection in integrated amperometric mode, with the normal preloaded wave form for sugar detection (Dionex Corp., 1994). Detector output range was set to $100 \mathrm{nC}$. Isocatric elution was carried out with $40 \mathrm{mmol} / \mathrm{L} \mathrm{NaOH}(50 \%$ solution obtained from J. T. Baker, Deventer, The Netherlands) at a flow rate of $1 \mathrm{~mL} / \mathrm{min}$ and a temperature of $24^{\circ} \mathrm{C}$. Two independent HPLC measurements were done for each sample, and results of replicates were averaged for the analyses. Retention times were calibrated daily for D-glucose, D-fructose, and sucrose (Sigma-Aldrich, Madrid, Spain) by injecting $10 \mathrm{~mL}$ of a calibration mixture containing $5.5 \mathrm{ppm}, 13.75 \mathrm{ppm}$, and $13.75 \mathrm{ppm}$ of these sugars, respectively. Only sucrose, glucose, and fructose appeared in the analyses. For each nectar sample, the proportions of glucose, fructose, and sucrose were determined by integrating the area under the chromatogram peaks.

Statistical analyses-Statistical analyses were conducted using the SAS program (version 9.2, SAS Institute, Cary, North Carolina, USA). Differences in the content of the individual sugars between ant-exposed and ant-excluded flowers, between $C$. hypocistis races, and between floral sexes were analyzed by fitting generalized linear mixed models with Gaussian distribution of errors and identity link function (Proc MIXED). The effect of ascomycetous and basidiomycetous yeasts in the glucose, fructose, and sucrose content was analyzed using a generalized linear mixed model (Proc MIXED). Data on sucrose, glucose, and fructose content were log-transformed to achieve normality. Races and sex were treated as fixed effects and populations and plants as random effect in the models.

Correlations between yeast cell density and fructose, glucose, or sucrose content in nectar samples were estimated by Spearman's rank correlation test with the CORR procedure. Within each plant set (ant-exposed or control), glucose and fructose content was compared by the nonparametric Wilcoxon test. All means and associated standard errors reported are model-corrected means calculated with the LSMEANS statement.

\section{RESULTS}

Controlled ant-exclusion experiments-Nectar of flowers exposed to ants contained significantly more fructose (mean \pm $\mathrm{SE}=21.0 \pm 1.1$ vs. $9.6 \pm 1.3 \% ; P<0.0001)$, more glucose $(14.8 \pm$ 1.2 vs. $8.9 \pm 1.4 \% ; P=0.0003)$, and less sucrose $(60.3 \pm 1.6$ vs. $79.6 \pm 1.9 \% ; P<0.0001)$ than nectar of ant-excluded flowers $(N=278$; Table 1). No differences between male and female flowers were detected for the proportion of individual sugars content $(P>0.13$ in all cases), but there was a significant effect of the identity of the race of $C$. hypocistis in the carbohydrates content $(P<0.0001$ in all cases; Table 1$)$. Statistical significance of the exclusion $\times$ race interaction effect revealed that the impact of ant exclusion on the proportion of individual sugars did not remain consistent across the three races; hence, the antexclusion experiments were tested separately for each race.

When the three races of $C$. hypocistis were analyzed separately, a pattern similar to that previously observed was detected in two races. Ant-exposed race Hh flowers contained more

TABLE 1. Summary of generalized linear model testing for the effect of ant exclusion, plant race, and flower sex on the relative amount of individual sugars (glucose, fructose, sucrose) in Cytinus hypocistis nectar samples.

\begin{tabular}{lcccccccc}
\hline \hline \multirow{2}{*}{ Source of variation } & \multicolumn{2}{c}{ Glucose $(\%)$} & & \multicolumn{2}{c}{ Fructose $(\%)$} & & \multicolumn{2}{c}{ Sucrose (\%) } \\
\cline { 2 - 3 } & $F$ & $P$ & & $F$ & $P$ & & $F$ & $P$ \\
\hline Ant exclusion & 13.7 & 0.0003 & & 132.7 & $<0.0001$ & & 57.4 & $<0.0001$ \\
Race & 32.7 & $<0.0001$ & & 30.3 & $<0.0001$ & & 33.4 & $<0.0001$ \\
Sex & 0.32 & 0.57 & & 2.4 & 0.13 & & 1.51 & 0.22 \\
Exclusion $\times$ race & 1.18 & 0.31 & & 8.44 & 0.0003 & & 6.42 & 0.002 \\
\hline
\end{tabular}



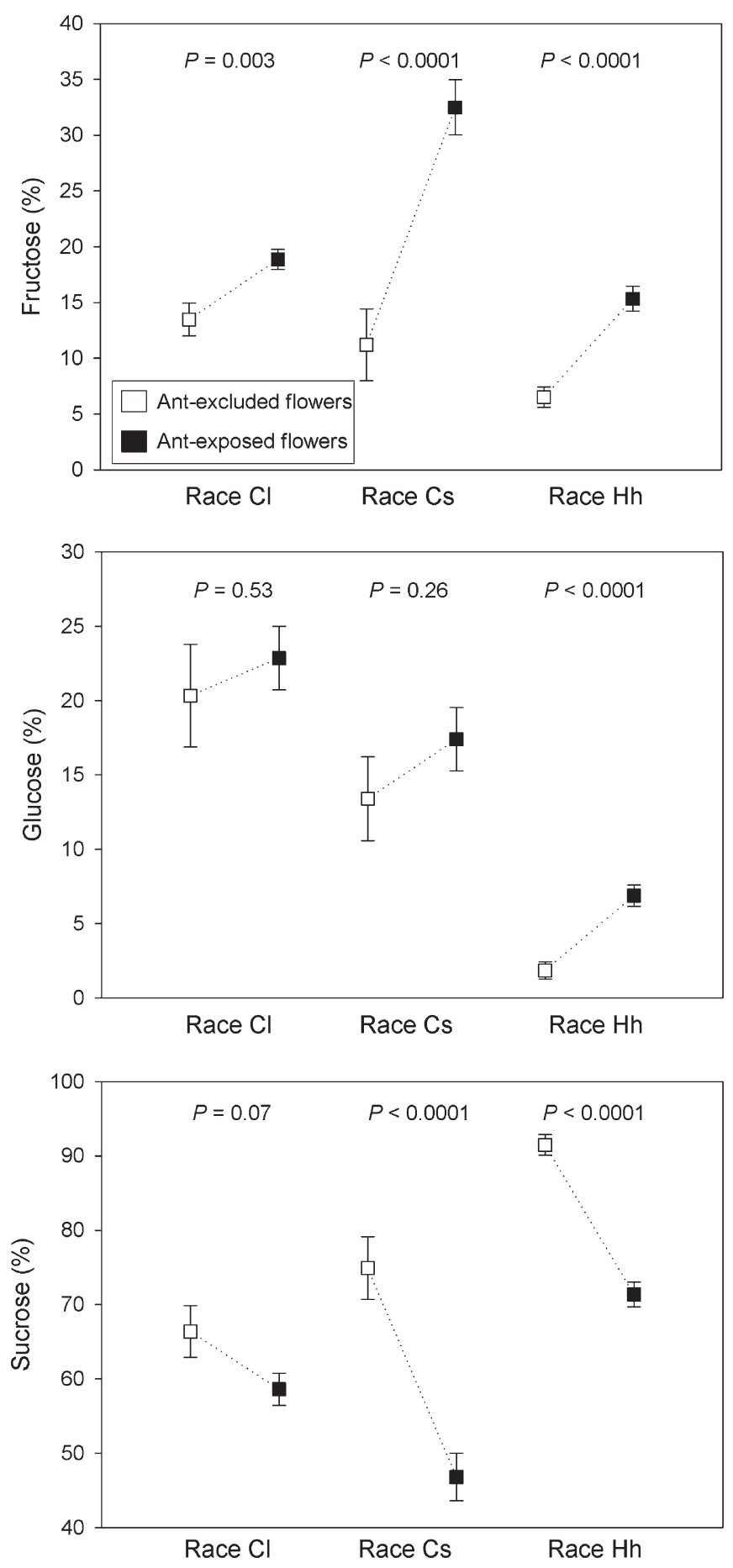

Fig. 2. Variations in the proportion of glucose, fructose, and sucrose between nectar samples of ant-excluded (white symbols) and ant-exposed flowers (black symbols) in three races of Cytinus hypocistis. Symbols represent mean values and vertical bars represent standard errors. Abbreviations: $\mathrm{Cl}$, race parasitizing Cistus ladanifer; $\mathrm{Cs}$, on Cistus salviifolius; $\mathrm{Hh}$, on Halimium halimifolium. Note the different scaling of the $y$-axes. sucrose content $\left(F_{1,72}=28.07, P<0.0001\right)$ than nonvisited flowers; the percentage of glucose was similar for the two sets of flowers $\left(F_{1,72}=1.3, P=0.26\right)$. However, in race $\mathrm{Cl}$ the quantities of glucose $\left(F_{1,71}=0.39, P=0.53\right)$ and sucrose $\left(F_{1,71}=3.61, P=0.07\right)$ were statistically similar in flowers regardless of exposure to ants; only fructose content was higher in ant-exposed flowers $\left(F_{1,71}=9.72, P=0.003\right)$ (Fig. 2$)$. There were no statistical differences between populations for the proportion of individual sugars on nectar in any of the three races $(P>0.2$ in all cases). The exclusion $\times$ population interaction effect was not statistically significant in any of the three races $(P>0.3$ in all cases $)$.

Stoichiometry of hexoses in nectar samples-In nectar samples collected from non-exposed flowers, glucose and fructose concentrations were not different from each other in races $\mathrm{Cl}$ $(Z=1.42, P=0.16, N=27)$ and Cs $(Z=1.01, P=0.31, N=38)$, but they differed slightly in race Hh flowers, with both sugars at low concentrations in the samples (mean $2 \%$ of glucose and $6 \%$ fructose; $Z=5.78, P<0.001, N=44$ ) (Fig. 2). In contrast, fructose of nectar samples from ant-exposed flowers doubled the glucose content in race Cs $(32.5 \% \pm 2.5$ vs. $17.4 \pm 2.1$ respectively, $Z=6.37, P<0.0001, N=66)$ and $\mathrm{Hh}(15.3 \% \pm 1.1 \mathrm{vs}$. $6.8 \pm 0.7$ respectively, $Z=4.78, P<0.0001, N=30$ ) (Fig. 2 ), not supporting the exclusive activity of the invertase enzyme for depicting the observed patterns.

Relationships of sugar content with yeast density-The effects on nectar sugar composition of experimental manipulation were confirmed in the subset of flowers exposed to ants. In ant-exposed flowers, variation in individual sugars content was correlated with variation in yeast cell density. Percentage of fructose increased $\left(r_{\mathrm{s}}=0.32, P=0.0002, N=137\right)$ and percentage of sucrose decreased $\left(r_{\mathrm{s}}=-0.27, P=0.0015, N=137\right)$ with increasing yeast cell density (Fig. 3 ). When analyses were conducted separately for each race, the percentage of fructose increased, and the percentage of sucrose declined with increasing yeast cell density in race $\mathrm{Cs}\left(r_{\mathrm{s}}=0.40, P=0.006\right.$ for fructose; $r_{\mathrm{s}}=-0.30, P=0.044$ for sucrose, $\left.N=45\right)$ and race $\mathrm{Hh}\left(r_{\mathrm{s}}=0.5\right.$, $P=0.014$ for fructose; $r_{\mathrm{s}}=-0.5, P=0.012$ for sucrose, $N=26$ ). The Spearman rank correlation tests between individual sugars content and yeast cell density were not significant for race $\mathrm{Cl}$ $(P>0.21$ in all cases, $N=66)$.

Importance of yeast identity-Nectar of ant-exposed flowers harboring ascomycetous yeasts (including the genera Metschnikowia, Candida, and Debaryomyces) contained significantly more fructose $\left(F_{1,18}=4.65, P=0.04, N=45\right)$ less sucrose $\left(F_{1,18}=4.79, P=0.04, N=45\right)$, and similar amount of glucose $\left(F_{1,18}=0.34, P=0.56, N=45\right)$ than nectar of flowers harboring basidiomycetous yeasts (including the genera Cryptococcus, Rhodotorula, and Sporobolomyces) (Fig. 4).

In nectar samples containing ascomycetous yeasts, the fructose percentage increased $\left(r_{\mathrm{s}}=0.59, P=0.001, N=28\right)$ and sucrose percentage decreased significantly $\left(r_{\mathrm{s}}=-0.44, P=0.02, N=28\right)$ with increasing yeast density (Fig. 5). However, for samples containing only basidiomycetous yeasts, correlations between sugar content and yeast density were not significant $(P>0.6, N=15)$.

\section{DISCUSSION}

Controlled ant-exclusion experiments have provided compelling evidence that ant foraging has the potential to change glucose $\left(F_{1,51}=91.01, P<0.0001\right)$, more fructose $\left(F_{1,51}=66.4\right.$, non-exposed flowers (Fig. 2). Similarly, race Cs flowers visited by ants had higher fructose $\left(F_{1,72}=69.2, P<0.0001\right)$ and lower 

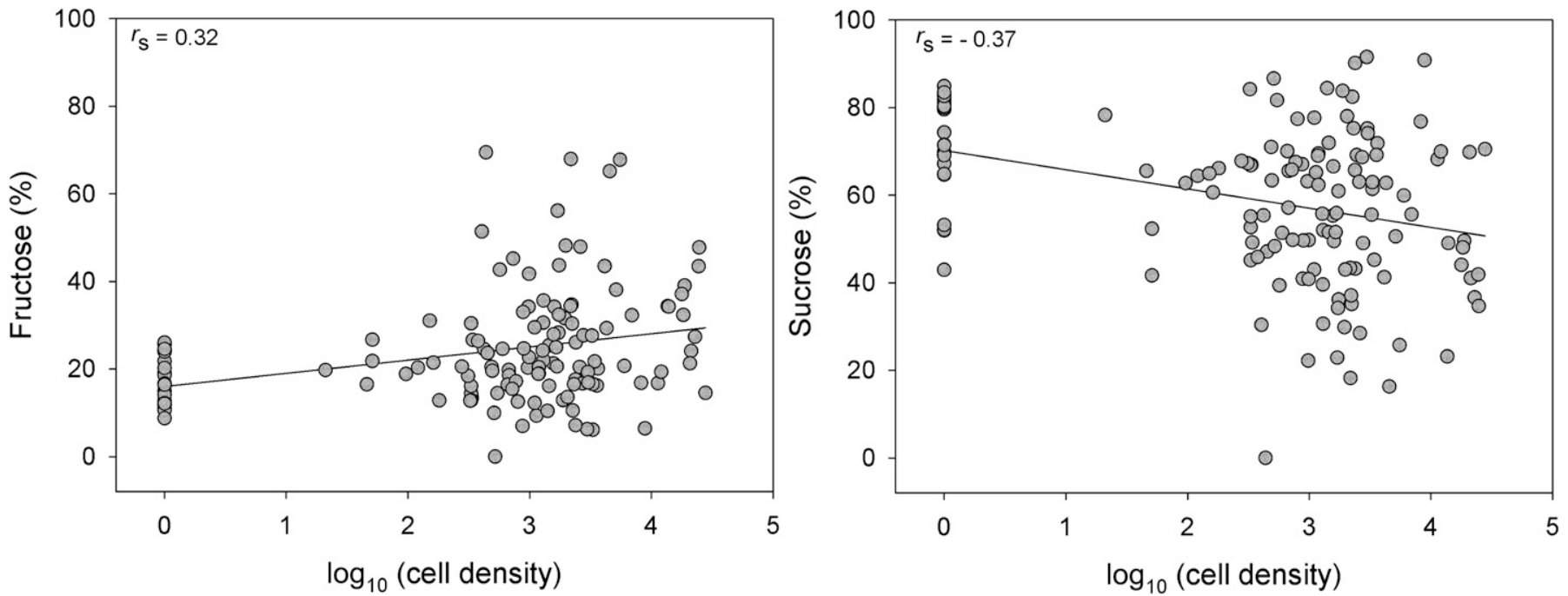

Fig. 3. Relationships between percentage fructose and sucrose and yeast cell density in nectar samples of Cytinus hypocistis flowers exposed to ant visits. All six populations were pooled. The relationship was significantly positive for fructose (Spearman's $P=0.0002)$ and negative for sucrose (Spearman's $P=0.002$ ). Each symbol corresponds to a single-flower nectar sample. Line is the least-squares-adjusted regression.

nectar chemical characteristics through microbe vectoring. Nectar of flowers visited by ants contained significantly more fructose, more glucose and less sucrose than nectar of antexcluded flowers, these differences being correlated with the identity of the yeast transported by ants and with their density in nectar. Beyond the conspicuous mutualistic and antagonistic ant-plant interactions including pollination, herbivory, plant defense, or seed dispersal (Beattie, 1985; Heil and McKey, 2003; Rico-Gray and Oliveira, 2007), our findings reveal a novel role for ants in plant communities. Considering the ubiquity of ants as nectar consumers in most terrestrial ecosystems, their invisible activity as indirect nectar modifiers is likely to be widespread.

Factors influencing ant-induced nectar changes-The magnitude of the effects of nectar chemical changes induced by

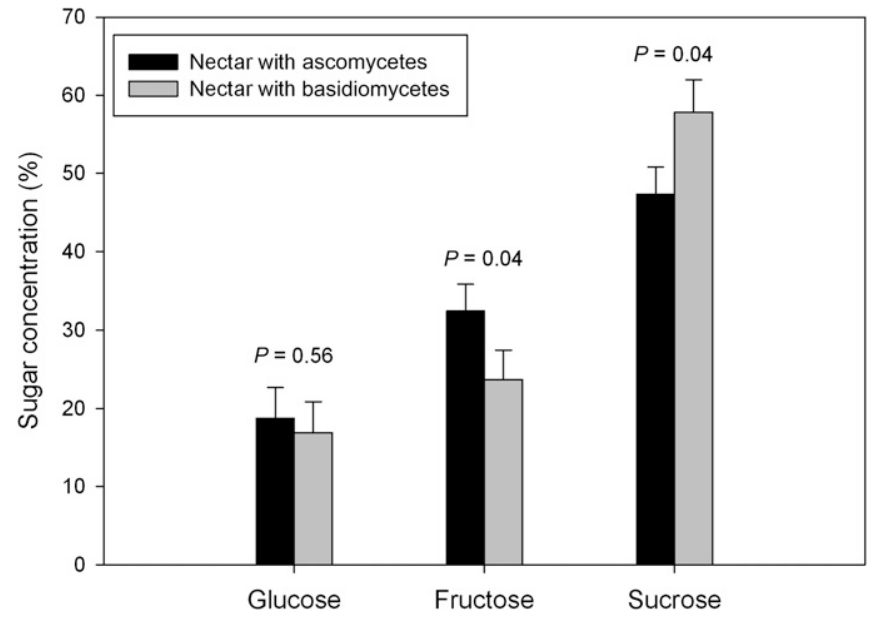

Fig. 4. Differences in glucose, fructose, and sucrose concentration between nectar samples of Cytinus hypocistis containing ascomycetous (black bars) or basidiomycetous yeasts (gray bars). Graphs depict means \pm SE. ants will depend on several factors. The effectiveness of particular ant species in transferring yeasts is a first point to be considered. While some ant species, such as Camponotus pilicornis, have been shown to be poor yeast dispersal agents, others such as Aphaenogaster senilis, Crematogaster auberti, Pheidole pallidula, and Plagiolepis pygmaea clearly favor yeast dispersal to flowers (de Vega and Herrera, 2012). These four species will potentially induce greater changes in nectar sugar composition through their activity as yeast dispersers, so that the more visits and the higher the density of yeast transported, the greater the changes in nectar sugar composition. Another important point to consider is the identity of the transported yeast taxa. In $C$. hypocistis nectar, the percentage of fructose increases and the percentage of sucrose decreases with increasing yeast cell density, as previously observed for bee-pollinated plants (Herrera et al., 2008). This was the case for populations of $C$. hypocistis in races $\mathrm{Cs}$ and $\mathrm{Hh}$. However, in race $\mathrm{Cl}$, which had the lowest yeast cell densities and the lowest presence of ascomycetes, there was no correlation between the amount of individual sugars and yeast cell density. Ants transport both ascomycetes and basidiomycetes to flowers (de Vega and Herrera, 2012), but we have here demonstrated that nectar of ant-visited flowers that harbor ascomycetous yeasts contained significantly more fructose and less sucrose than nectar of flowers harboring basidiomycetous yeasts. Moreover, while for ascomycetous yeasts, the higher the density of cells, the higher was the percentage of fructose and the lower the percentage of sucrose. For basidiomycetes, cell density was not correlated with changes in nectar sugar constituents. Thus, the species composition and physiological characteristics of the transported yeasts emerge as a crucial driving factor in nectar changes, a possibility tentatively suggested by Canto and Herrera (2012).

It is not surprising that in $C$. hypocistis, ascomycetous yeasts induce more changes and grow to higher densities. Ascomycetous yeasts can reach high cell densities in nectar (BryschHerzberg, 2004; Pozo et al., 2012; de Vega and Herrera, 2012) since the sugar concentration of nectar favors osmotolerant and fermentative species more frequently found in the order Saccharomycetales, such as the genus Metschnikowia, Candida, and 

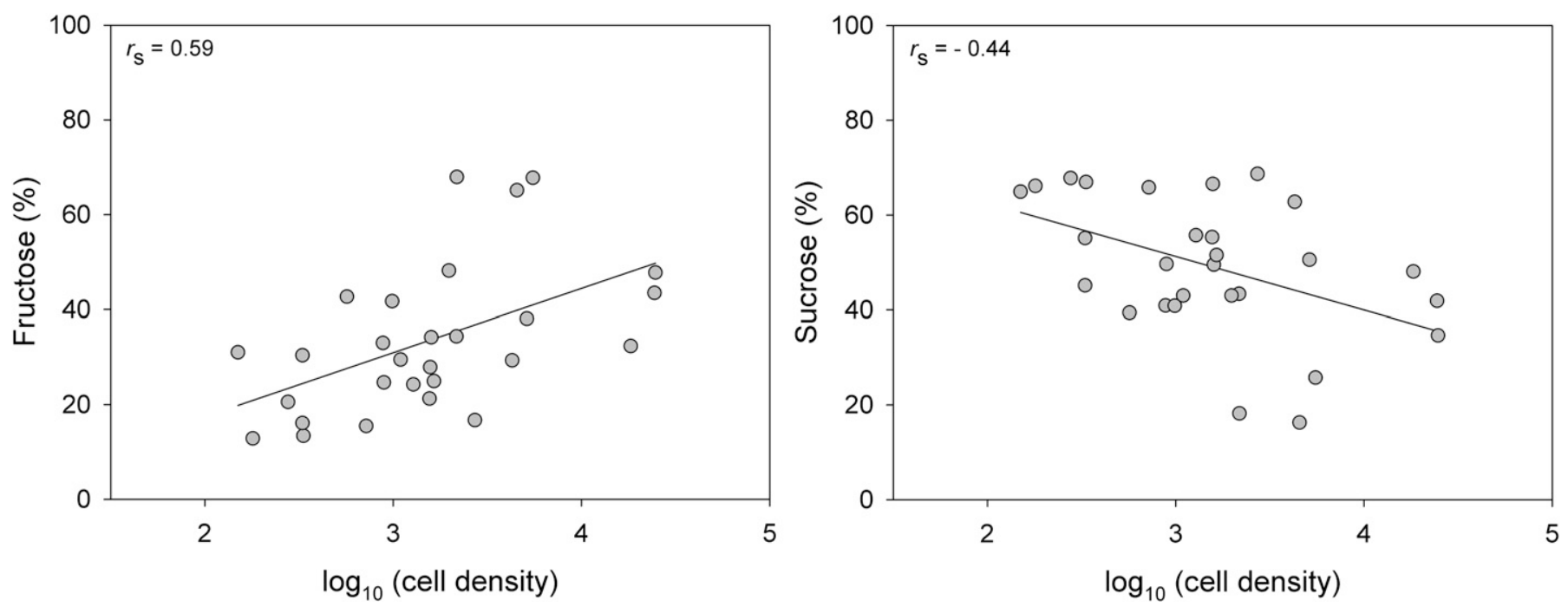

Fig. 5. Relationships between percentage fructose and sucrose and yeast cell density in nectar samples of Cytinus hypocistis flowers containing ascomycetous yeasts. The relationship is significantly positive for fructose (Spearman's $P=0.001$ ) and negative for sucrose (Spearman's $P=0.014$ ). For samples containing basidiomycetous yeasts correlations are not significant $\left(r_{\mathrm{s}}=-0.08, P=0.78\right.$ for fructose and $r_{\mathrm{s}}=0.08, P=0.79$ for sucrose $)$. Each symbol corresponds to a single-flower nectar sample. Line is the least-squares-adjusted regression.

Debaryomyces (Lachance, 2006), which were observed in the nectar of $C$. hypocistis. Even some of the ascomycetous yeasts were nectar specialists (de Vega and Herrera, 2012). In turn, in the basidiomycetes isolated from C. hypocistis nectar (Rhodotorula, Cryptococcus, and Sporobolomyces), carbohydrate metabolism is not fermentative (Kurtzman et al., 2011). Further factors that can regulate potential nectar changes induced by ants are due to a combination of chemical characteristics of the plant species. Nectar is a sugar-rich solution and a good medium for microbe growth, and the presence of secondary compounds and proteins such as nectarins that confer nectar antibiotic properties can protect plants from microbial proliferation (Adler, 2000; Carter and Thornburg, 2004; GonzálezTeuber et al., 2009) and thus from potential chemical changes in nectar.

Microbial degradation of nectar and invertase activity-Our experimental study under natural conditions has provided conclusive evidence that nectar sugar composition is not completely controlled by the plant and that this crucial food source may be influenced by external microbial factors. We have thereby confirmed the prediction of previous correlational studies that had no experimental manipulations (Canto et al., 2008; Herrera et al., 2008; Canto and Herrera, 2012). Traditionally, the relative amounts of glucose and fructose in nectar have been assumed to result almost exclusively from the activity of the invertase enzyme that hydrolyzes sucrose in the nectary (Nicolson and Thornburg, 2007; Heil, 2011). However, nectar sugar composition observed in C. hypocistis cannot be supported exclusively by the sucrose-cleaving activity of invertase for several reasons. First, chemical analyses revealed that nectar of ant-excluded flowers contained mainly sucrose, whereas nectar of ant-visited flowers showed a proportion of sucrose reduced by up to $47 \%$, and a high increase in monosaccharides that could be explained by hydrolysis of the disaccharides into monosaccharides by yeast metabolism (D'Amore et al., 1989). Second, nectar of ant-excluded flowers contained approximately equal amounts of glucose and fructose, as expected from the simple action of invertase. However, nectar of ant-visited flowers of races $\mathrm{Cs}$ and $\mathrm{Hh}$ contained significantly higher proportions of fructose, likely due to a preferential or more rapid metabolism of glucose over fructose such as occurs in many ascomycetes (D'Amore et al., 1989; Berthels et al., 2004) and to the fermentation of glucose by the dominant ascomycetes in the genera Metschnikowia and Candida (Kurtzman et al., 2011). However in C. hypocistis race $\mathrm{Cl}$, in which stoichiometric proportions of hexoses were observed, nectar microbiota was dominated by the basidiomycetous genera Cryptococcus, Rhodotorula, and Sporobolomyces, in which glucose fermentation ability is absent (Kurtzman et al., 2011), supporting the hypothesis that ascomycetous yeast metabolism is more important for nectar chemical changes. Other possible explanations for the deviation from a 1:1 ratio have been proposed, such as the selective reabsorption of monosaccharides and their cycling (Nepi and Stpiczynska, 2008; Wenzler et al., 2008), but if these mechanisms actually operated in $C$. hypocistis, the relative proportions of monosaccharides should be similar in ant-exposed and ant-excluded flowers, and this is not the case.

Ecological implications-Herrera et al. (2013) have empirically demonstrated that nectar-dwelling yeasts, and more specifically ascomycetous yeasts, can alter pollinator behavior and negatively influence pollination success and maternal fecundity, with a reduction in the number of pollen tubes in the style, fruit set, seed set, and seed mass. On the basis of these findings, we can hypothesize that besides the expected effects of alteration of the sugar profile and drastic reduction in total carbohydrate content (de Vega and Herrera, 2012), ant-transported yeasts may potentially further alter the foraging choices of pollinators that subsequently visit the flowers and ultimately affect plant reproduction. We have here shown the effects of ants and the relative importance of their different associated yeasts on the nectar sugar profile in an ant-pollinated plant, but their effects on other pollinators were beyond the scope of the present study. However, several ant species that visited Cytinus flowers, such as Aphaenogaster senilis, Pheidole pallidula, 
Crematogaster auberti, or Plagiolepis pygmaea, are frequent nectar consumers on many plants in different habitats and share flower resources with different arrays of pollinators (Herrera et al., 1984; Gómez et al., 1996; Cursach and Rita, 2012). Since it is well known that foraging preferences of pollinators are sensitive to variations in nectar sugar constituents (Nicolson, 2007; Escalante-Pérez and Heil, 2012), our results suggest that these ants, at least, should not be viewed simply as nectar consumers, but as yeast vectors that can be carrying out an important but invisible activity. Ants may therefore modify pollinator visitation not only by their presence or aggressive behavior (Tsuji et al., 2004; Ness, 2006; Junker et al., 2007), but also by inducing indirect chemical changes in this main food source through yeast vectoring. Depending on the plant species and the pollinator community, the effects of ant foraging activity on nectar traits may potentially shift from negative to positive or have no discernible consequences.

Concluding remarks-To summarize, our experimental results demonstrate that the exposure of floral nectars to ants and their associated microorganisms leads to important nectar changes, with a decrease in sucrose and an increase in fructose and glucose content. Given that yeast inoculation may be an inevitable sequel of ant visits, especially if they occur at high frequency, the importance of these visits should not be minimized. It has been previously demonstrated that yeasts may further increase nectar osmolalities (since hexose nectars are osmotically more concentrated that sucrose nectars; Nicolson, 2002), reduce sugar and amino acid concentration (Herrera et al., 2008; de Vega and Herrera, 2012; Peay et al., 2012), and produce alcohol (Ehlers and Olesen, 1997; Wiens et al., 2008) and a variety of fermentation volatiles (Raguso, 2004) with potential impacts on pollination success. We have demonstrated that the magnitude of the effects of ant visits on nectar depends directly on the identity and density of the yeasts dispersed and the ant species involved. Whether ants and their associated yeasts inflict a fitness costs on plant with which they associate will be dependent on the role played as mutualist or exploiter, ant abundance, ant-activity patterns, effects on floral attraction, and impact on pollinator behavior. Because of the complexity and context dependency of ant-yeast-plantpollinator interactions, it is still premature to draw general conclusions about the effect of ants on plant reproduction through their indirect effect on nectar chemical modification. Further research will provide a deeper understanding of the ecological processes and interactions among species from these three different kingdoms.

\section{LITERATURE CITED}

AdLER, L. S. 2000. The ecological significance of toxic nectar. Oikos 91: 409-420.

BAKER, H. G., AND I. BAKER. 1983. Floral nectar sugar constituents in relation to pollinator type. In C. E. Jones and R. J. Little [eds.], Handbook of pollination biology, 117-141. Van Nostrand Reinhold, New York, New York, USA.

Beattie, A. J. 1985. The evolutionary ecology of ant-plant mutualisms. Cambridge University Press, Cambridge, UK.

Beattie, A. J., and L. Hughes. 2002. Ant-plant interactions. In C. M. Herrera and P. O. Pellmyr [eds.], Plant-animal interactions: An evolutionary approach, 211-235. Blackwell Science, Oxford, UK.

Beattie, A. J., C. Turnbull, R. B. Knox, and E. G. Williams. 1984. Ant inhibition of pollen functions: A possible reason why ant pollination is rare. American Journal of Botany 71: 421-426.
Berthels, N. J., R. R. Cordero Otero, F. F. Bauer, J. M. Thevelein, And I. S. Pretorius. 2004. Discrepancy in glucose and fructose utilisation during fermentation by Saccharomyces cerevisiae wine yeast strains. FEMS Yeast Research 4: 683-689.

Blüthgen, N., AND K. Fiedler. 2004. Preferences for sugars and amino acids and their conditionality in a diverse nectar-feeding ant community. Journal of Animal Ecology 73: 155-166.

BlüthGen, N., N. E. STORK, AND K. FiedLer. 2004. Bottom-up control and co-occurrence in complex communities: Honeydew and nectar determine a rainforest ant mosaic. Oikos 106: 344-358.

Blüthgen, N., M. Verhaagh, W. Goitía, K. Jaffé, W. Morawetz, and W. BARThLOOT. 2000. How plants shape the ant community in the Amazonian rainforest canopy: The key role of extrafloral nectaries and hemipteran honeydew. Oecologia 125: 229-240.

Bosch, J., J. Retana, and X. CerdÁ. 1997. Flowering phenology, floral traits, and pollinator composition in a herbaceous Mediterranean plant community. Oecologia 109: 583-591.

BrysCH-Herzberg, M. 2004. Ecology of yeasts in plant-bumblebee mutualism in Central Europe. FEMS Microbiology Ecology 50: $87-100$

CAnto, A., ANd C. M. Herrera. 2012. Micro-organisms behind the pollination scenes: Microbial imprint on floral nectar sugar variation in a tropical plant community. Annals of Botany 110: 1173-1183.

Canto, A., C. M. Herrera, M. Medrano, R. Pérez, and I. M. García. 2008. Pollinator foraging modifies nectar sugar composition in Helleborus foetidus L. (Ranunculaceae): An experimental test. American Journal of Botany 95: 315-320.

CARTer, C., AND R. W. Thornburg. 2004. Is the nectar redox cycle a floral defense against microbial attack? Trends in Plant Science 9: 320-324.

CuRsach, J., And J. Rita. 2012. Reproductive biology of Ranunculus weyleri (Ranunculaceae), a narrowly endemic plant from the Balearic Islands with disjunct populations. Flora 207: 726-735.

D’Amore, T., I. Russell, and G. G. Stewart. 1989. Sugar utilization by yeast during fermentation. Journal of Industrial Microbiology 4: 315-324.

DE VEGA, C. 2007. Reproductive biology of Cytinus hypocistis (L.) L.: Host-parasite interactions. Ph.D. dissertation, University of Seville, Seville, Spain.

de Vega, C., M. Arista, P. L. Ortiz, C. M. Herrera, and S. Talavera. 2009a. The ant-pollination system of Cytinus hypocistis (Cytinaceae), a Mediterranean root holoparasite. Annals of Botany 103: 1065-1075.

de Vega, C., M. Arista, P. L. Ortiz, C. M. Herrera, and S. Talavera. 2011. Endozoochory by beetles: A novel seed dispersal mechanism. Annals of Botany 107: 629-637.

de Vega, C., M. Arista, P. L. Ortiz, and S. Talavera. 2010. Anatomical relations among endophytic holoparasitic angiosperms, autotrophic host plants and mycorrhizal fungi: A novel tripartite interaction. American Journal of Botany 97: 730-737.

de Vega, C., R. Berjano, M. Arista, P. L. Ortiz, S. Talavera, and T. F. Stuessy. 2008. Genetic races associated with the genera and sections of host species in the holoparasitic plant Cytinus (Cytinaceae) in the Western Mediterranean basin. New Phytologist 178: 875-887.

de Vega, C., B. Guzmán, M. A. Lachance, S. L. Steenhuisen, S. D. Johnson, and C. M. Herrera. 2012. Metschnikowia proteae sp. nov., a nectarivorous insect-associated yeast species from Africa. International Journal of Systematic and Evolutionary Microbiology 62: $2538-2545$

de Vega, C., And C. M. Herrera. 2012. Relationships among nectardwelling yeasts, flowers and ants: Patterns and incidence on nectar traits. Oikos 121: 1878-1888.

de Vega, C., C. M. Herrera, and S. D. Johnson. 2009b. Yeasts in floral nectar of some South African plants: quantification and associations with pollinator type and sugar concentration. South African Journal of Botany 75: 798-806.

de Vega, C., P. L. Ortiz, M. Arista, and S. Talavera. 2007. The endophytic system of Mediterranean Cytinus (Cytinaceae) developing on five host Cistaceae species. Annals of Botany 100: 1209-1217. 
DiONEX CORP. 1994. Optimal setting for pulsed amperometric detection of carbohydrates using Dionex pulsed electrochemical and amperometric detectors. Dionex, Sunnyvale, California, USA.

Ehlers, B. K., ANd J. M. Olesen. 1997. The fruit-wasp route to toxic nectar in Epipactis orchids? Flora 192: 223-229.

Escalante-Pérez, M., and M. Heil. 2012. Nectar secretion: Its ecological context and physiological regulation. In J. M. Vivanco and F. Baluška [eds.], Secretions and exudates in biological systems, vol. 12, Signaling and communication in plants, 187-220. Springer, Berlin, Germany.

FREEMAN, C. E., AND D. H. WiLKEN. 1987. V Variation in nectar sugar composition at the intraplant level in Ipomopsis longiflora (Polemoniaceae). American Journal of Botany 74: 1681-1689.

FritZ, R. S., AND D. H. Morse. 1981. Nectar parasitism of Asclepias syriaca by ants: Effect on nectar levels, pollinia insertion, pollinaria removal, and pod production. Oecologia 50: 316-319.

Galen, C., AND B. Butchart. 2003. Ants in your plants: Effects of nectarthieves on pollen fertility and seed-siring capacity in the alpine wildflower, Polemonium viscosum. Oikos 101: 521-528.

Galetto, L., AND G. Bernardello. 2003. Nectar sugar composition in angiosperms from Chaco and Patagonia (Argentina): An animal visitor's matter? Plant Systematics and Evolution 238: 69-86.

Galetto, L., and G. Bernardello. 2005. Rewards in flowers: Nectar. In A. Dafni, P. G. Kevan, and B. C. Husbands [eds.], Practical pollination biology, 261-313. Enviroquest, Cambridge, UK.

Ghazoul, J. 2001. Can floral repellents pre-empt potential ant-plant conflicts? Ecology Letters 4: 295-299.

Goldblatt, P., J. C. Manning, and P. Bernhardt. 2001. Radiation of pollination systems in Gladiolus (Iridaceae: Crocoideae) in southern Africa. Annals of the Missouri Botanical Garden 88: 713-734.

GómeZ, J. M., AND R. ZAMORA. 1992. Pollination by ants: Consequences of the quantitative effects on a mutualistic system. Oecologia 91: $410-418$

Gómez, J. M., R. Zamora, J. A. Hódar, And D. García. 1996. Experimental study of pollination by ants in Mediterranean high mountain and arid habitats. Oecologia 105: 236-242.

González-Teuber, M., S. Eilmus, A. Muck, A. Svatos, and M. Heil. 2009. Pathogenesis-related proteins protect extrafloral nectar from microbial infestation. Plant Journal 58: 464-473.

Guerrant, E. O., And P. L. FiedLer. 1981. Flower defenses against nectar-pilferage by ants. Biotropica 13: 25-33.

Haber, W. A., G. W. Frankie, H. G. Baker, I. Baker, and S. Koptur. 1981. Ants like flower nectar. Biotropica 13: 211-214.

HeIL, M. 2011. Nectar: Generation, regulation, and ecological functions. Trends in Plant Science 16: 191-200.

Heil, M., B. Fiala, B. Baumann, and K. E. Linsenmair. 2000. Temporal, spatial and biotic variations in extrafloral nectar secretion by Macaranga tanarius. Functional Ecology 14: 749-757.

Heil, M., And D. McKey. 2003. Protective ant-plant interactions as model systems in ecological and evolutionary research. Annual Review of Ecology, Evolution and Systematics 34: 425-453.

Heil, M., J. RattKe, And W. Boland. 2005. Postsecretory hydrolysis of nectar sucrose and specialization in ant/plant mutualism. Science 308: $560-563$

Herrera, C. M., C. de Vega, A. Canto, and M. I. Pozo. 2009. Yeasts in floral nectar: A quantitative survey. Annals of Botany 103: $1415-1423$.

Herrera, C. M., I. M. García, and R. Pérez. 2008. Invisible floral larcenies: Microbial communities degrade floral nectar of bumble beepollinated plants. Ecology 89: 2369-2376.

Herrera, C. M., J. Herrera, and X. Espadaler. 1984. Nectar thievery by ants from southern Spanish insect-pollinated flowers. Insectes Sociaux 31: 142-154.

Herrera, C. M., R. Pérez, and C. Alonso. 2006. Extreme intraplant variation in nectar sugar composition in an insect-pollinated perennial herb. American Journal of Botany 93: 575-581.

Herrera, C. M., M. I. Pozo, and M. Medrano. 2013. Yeasts in nectar of an early-blooming herb: Sought by bumble bees, detrimental to plant fecundity. Ecology. doi:10.1890/12-0595.1
Hickman, J. C. 1974. Pollination by ants: A low-energy system. Science 184: 1290-1292.

Huxley, C. R., AND D. F. CutLer. 1991. Ant-plant interactions. Oxford University Press, Oxford, UK.

JunkeR, R., A. Y. C. Chung, AND N. BlÜThgen. 2007. Interactions between flowers, ants and pollinators: additional evidence for floral repellence against ants. Ecological Research 22: 665-670.

Krömer, T., M. Kessler, G. Lohaus, and A. N. Schmidt-Lebuhn. 2008. Nectar sugar composition and concentration in relation to pollination syndromes in Bromeliaceae. Plant Biology 10: 502-511.

Kurtzman, C. P., J. W. Fell, and T. Boekhout. 2011. The yeasts, a taxonomic study, 5th ed. Elsevier, London, UK.

Lachance, M. A. 2006. Yeast biodiversity: How many and how much? In C. A. Rosa and G. Peter [eds.], Biodiversity and ecophysiology of yeasts, 1-9. Springer-Verlag, Berlin, Germany.

Manson, J. S., M. A. Lachance, and J. D. Thomson. 2007. Candida gelsemii sp. nov., a yeast of the Metschnikowiaceae clade isolated from nectar of the poisonous Carolina jessamine. Antonie van Leeuwenhoek 92: 37-42.

Nepi, M., and M. StPicZynska. 2008. The complexity of nectar: Secretion and resorption dynamically regulate nectar features. Naturwissenshaften 95: 177-184.

Nepi, M., P. von Aderkas, and E. Pacini. 2012. Sugary exudates in plant pollination. In J. M. Vivanco and F. Baluška [eds.], Secretions and exudates in biological systems, vol. 12, Signaling and communication in plants, 155-186. Springer, Berlin, Germany.

NESS, J. H. 2006. A mutualism's indirect cost: The most aggressive plant bodyguards also deter pollinators. Oikos 113: 506-514.

Nicolson, S. W. 2002. Pollination by passerine birds: Why are the nectars so dilute? Comparative Biochemistry and Physiology, B, Comparative Biochemistry 131: 645-652.

Nicolson, S. W. 2007. Nectar consumers. In S. W. Nicolson, M. Nepi, and W. Pacini [eds.], Nectaries and nectar, 289-342. Springer-Verlag, Dordrecht, Netherlands.

Nicolson, S. W., and R. W. Thornburg. 2007. Nectar chemistry. In S. W. Nicolson, M. Nepi, and W. Pacini [eds.], Nectaries and nectar, 215-264. Springer-Verlag, Dordrecht, Netherlands.

Norment, C. J. 1988. The effect of nectar-thieving ants on the reproductive success of Frasera speciosa (Gentianaceae). American Midland Naturalist 120: 331-336.

Oliveira, P. S., V. Rico-Gray, C. Díaz-Castelazo, and C. CastilloGuevara. 1999. Interaction between ants, extrafloral nectaries, and insect herbivores in neotropical coastal sand dunes: Herbivore deterrence by visiting ants increases fruit set in Opuntia stricta (Cactaceae). Functional Ecology 13: 623-631.

PACINI, E., AND S. W. Nicolson. 2001. Introduction. In S. W. Nicolson, M. Nepi, and W. Pacini [eds.], Nectaries and nectar, 1-18. SpringerVerlag, Dordrecht, Netherlands.

Peay, K. G., M. Belisle, and T. Fukami. 2012. Phylogenetic relatedness predicts priority effects in nectar yeast communities. Proceedings of the Royal Society, B, Biological Sciences 279: 749-758.

Pozo, M. I., C. M. Herrera, and P. Bazaga. 2012. Species richness of yeast communities in floral nectar of southern Spanish plants. Microbial Ecology 6: 82-91.

Puterbaugh, M. N. 1998. The roles of ants as flowers visitors: Experimental analysis in three alpine plant species. Oikos 83 : 36-46.

RAGUSO, R. A. 2004. Why are some floral nectars scented? Ecology 85: $1486-1494$.

Rico-Gray, V. 1989. The importance of floral and circum-floral nectar to ants inhabiting dry tropical lowlands. Biological Journal of the Linnean Society 38: 173-181.

Rico-Gray, V. 1993. Use of plant-derived food resources by ants in the dry tropical lowland of coastal Veracruz, Mexico. Biotropica 25: 301-315.

Rico-Gray, V., J. G. García-Franco, M. Palacios-Ríos, C. DíazCastelazo, V. Parra-Tabla, and J. A. Navarro. 1998. Geographical and seasonal variation in the richness of ant-plant interactions in Mexico. Biotropica 30: 190-200. 
Rico-Gray, V., AND P. S. Oliveira. 2007. The ecology and evolution of antplant interactions. University of Chicago Press, Chicago, Illinois, USA.

Rostás, M., AND J. TAUTZ. 2011. Ants as pollinators of plants and the role of floral scents. In Z. Dubinsky and J. Seckbach [eds.], All flesh is grass, 151-161. Springer, Berlin, Germany.

Tsuji, K., S. Hasyim, and H. K. Nakamura. 2004. Asian weaver ants, Oecophylla smaragdina, and their repelling of pollinators. Biological Research 19: 669-673.

Wenzler, M., D. Holscher, T. Oerther, and B. Schneider. 2008. Nectar formation and floral nectary anatomy of Anigozanthos flavidus: A combined magnetic resonance imaging and spectroscopy study. Journal of Experimental Botany 59: 3425-3434.

Wiens, F., A. Zitzmann, M. A. Lachance, M. Yegles, F. Pragst, F. M Wurst, D. von Holst, S. L. Guan, and R. Spanagel. 2008. Chronic intake of fermented floral nectar by wild treeshrews. Proceedings of the National Academy of Sciences, USA 105: 10426-10431.

Willmer, P., C. Nuttman, N. Raine, G. Stone, J. Pattrick, K. Henson, P. Stillman, L. McIlroy, S. Potts, and J. Knudsen. 2009. Floral volatiles controlling ant behaviour. Functional Ecology 23: 888-900. 